\title{
Usability Evaluation and Assessment of Computed Tomography Scan
}

\author{
Saad Aldoihi, Omar Hammami \\ Computer and System Engineering, ENSTA Paris, Palaiseau Cedex, France \\ Email: aldoihi@ensta.fr, hammami@ensta.fr
}

How to cite this paper: Aldoihi, S. and Hammami, O. (2020) Usability Evaluation and Assessment of Computed Tomography Scan. Intelligent Information Management, 12, 27-35.

https://doi.org/10.4236/iim.2020.121002

Received: October 23, 2019

Accepted: December 7, 2019

Published: December 10, 2019

Copyright $\odot 2020$ by author(s) and Scientific Research Publishing Inc. This work is licensed under the Creative Commons Attribution International License (CC BY 4.0).

http://creativecommons.org/licenses/by/4.0/

\begin{abstract}
Usability is a vital characteristic in operating medical machines, especially radiological machines, such as computed tomography (CT) scans and X-rays. The more the body is exposed to it, the greater the negative effect has. If usability is crucial to a specific industry, it is more crucial in the medical health industry due to its tremendous effect on safety and the patient's health. This study examines the usability of CT scans based on 14 attributes from hospitals across Saudi Arabia. The study revealed that usability consistency, visibility, minimalism, memory, and flexibility have the most usability catastrophic complaints, where the overall catastrophic rate exceeds $20 \%$. Creating a shortcut for frequently used operations is critically important, because it has a fundamental effect in minimizing physical and mental exertion.
\end{abstract}

\section{Keywords}

Usability Evaluation, CT Scan Usability Assessment, User Experience

\section{Introduction}

The usefulness of medical devices is marked by the extent to which they can execute tasks effectively, effortlessly, and easily. Advances in science and technology have made executing tasks increasingly complex. It requires years of learning and practice to efficiently operate modern medical devices, such as computed tomography (CT) scans or magnetic resonance imaging (MRI) [1]. A key contribution to such complexity is the fact that contemporary systems consist of multiple layers with extreme compatibility and intractability. When constituting a multi-layer system based on safety and security only, it becomes negative goals. Rather, it should constitute more layers to achieve overall functionality [2]. Moreover, [3] showed that the overall expectation of CT scan technological evo- 
lutions is to make the CT scan a more usable with a better user-friendly interface; however, the study showed that more technological evolution introduces increased complexity.

The general assumption for medical devices is that they ought to be usable and suited for their purpose [4]. To efficiently operate a CT scan requires adaptability with other systems, such as radiology information systems (RIS) or picture archiving and communication systems (PACSs). These systems integrate with a superior ecosystem called the hospital information system (HIS). The purpose of the HIS is to collect all patient records and make them retrievable by many of the hospital's applications [5]. Therefore, a CT scan operation is one component of an ecosystem. This isolated component has a tremendous effect on the overall ecosystem, and most importantly, it has a great effect on the indirect user (patient).

This paper will contribute to the general understanding of CT scan usability. Particularly, it explicitly focuses on technicians from Saudi Arabia. It observes and documents the usability encountered by technicians and provides recommendations to manufacturers and designers. The paper is structured as follows. Section 2 discusses the reality of the context of use within the operation of radiology. Section 3 discusses the study justification and objective. Section 4 details the methodology approach. Section 5 presents the results. Finally, Section 6 concludes the paper.

\section{Context of Use}

In general, usability is extremely essential to buyers because it brings certain benefits and, above all, contributes to maximizing safety. Furthermore, in the healthcare environment, usability is crucial because it contributes to safety and the prevention of errors. To [6], usability revolves only around the user, where the user should be involved, engaged, and doing something within the context of the product or system. Working in the healthcare environment makes one susceptible to extreme physical and mental loads as well as industry guidelines and requirements. Furthermore, [7] noted that usability is an essential attribute of safety. Thus, many industries tend to share this attribute [8] [9] [10].

Eventually, the context of use can be measured by calculating influential factors that affect (positively or negatively) the functionality of the product or users. The context of use covers a wide context of an organization's geopolitical atmospheres, such as requirement components and fitness for use (Figure 1). The workload can also negatively pressure the context of use. In addition, [11] has shown that the invisible workload can tremendously affect the working process of the CT scan operation. It was evident that radiologists seek minimal effort to divert invisible physical exertion after a certain operational time. Thus, radiologists maneuver the CT scan testing process so that they can avoid roving back and forth between the CT scan and the control room [12]. 


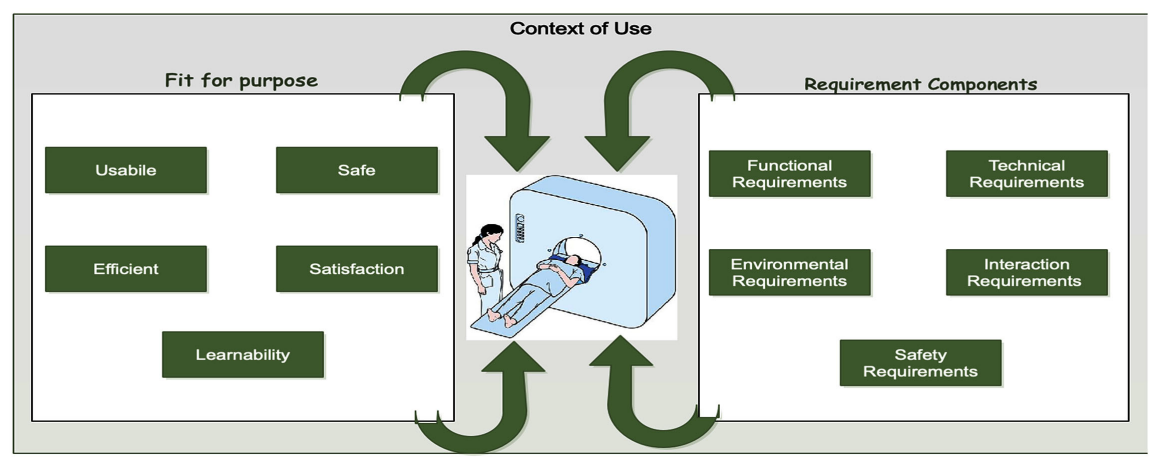

Figure 1. Context of use within the CT scan operation.

\section{Study Objectives}

Most usability evaluations that targeted healthcare in Saudi hospitals tend to discuss the obstacles of introducing new technologies. Nonetheless, literature progress that offers a sense of solution has been extremely limited. One fundamental reason is that many researchers have adopted their methods and evaluated attributes from a pure software perspective. It is fundamentally essential to examine and evaluate healthcare products based on the context of use and, in particular, involving the direct user (technician) and indirect user (patient) together. This study closely examines 14 usability attributes of the CT scan in Saudi hospitals. It also classifies the usability attributes based on severity. Understanding such severity is expected to help CT scan designers and manufacturers to improve future products to suit a specific market. In addition, the fundamental aim of this study is to explain the user's demographic differences where gender, age, education, and experience pose a threat in handling and operating the CT scan.

\section{Method}

To answer the research questions, a survey questionnaire was adopted. The research questions are 1) What usability attribute is deemed important to CT scan technicians? 2) What usability attribute do technicians have the most trouble with?

\subsection{Procedure}

The authors surveyed usability questionnaires that measured the lack of usability from different angles. The authors chose to adopt [4] because it was unambiguously intended for medical device use. The questionnaire measured 14 usability dimensions (Table 1). The responses to the questionnaire are based on a five-point Likert scale. Prior to the start, we conducted field observations in King Saud Medical City (KSMC). During the observation, the first author evaluated the operational usability in association with the everyday use and the applicability of the questionnaire to the CT scan context of use. The results were analyzed using SPSS 24 . 
Table 1. Usability attributes as defined by [4].

\begin{tabular}{|c|c|}
\hline Attribute & Explanation \\
\hline Consistency & $\begin{array}{l}\text { Consistency and standards: Users should not have to wonder whether different } \\
\text { words, situations, or actions mean the same thing. Standards and conventions in } \\
\text { product design should be followed. }\end{array}$ \\
\hline Visibility & $\begin{array}{l}\text { Visibility of system state: Users should be informed about what is going on with the } \\
\text { system through appropriate feedback and display of information. }\end{array}$ \\
\hline Match & $\begin{array}{l}\text { Match between system and world: The image of the system perceived by users should } \\
\text { match the model the users have about the system. }\end{array}$ \\
\hline Minimalist & $\begin{array}{l}\text { Minimalist: Any extraneous information is a distraction and a slow down the } \\
\text { process. }\end{array}$ \\
\hline Memory & $\begin{array}{l}\text { Minimize memory load: Users should not be required to memorize a lot of } \\
\text { information to carry out tasks. Memory load reduces the users' capacity to carry out } \\
\text { the main tasks. }\end{array}$ \\
\hline Feedback & $\begin{array}{l}\text { Informative feedback: Users should be given prompt and informative feedback about } \\
\text { their actions. }\end{array}$ \\
\hline Flexibility & $\begin{array}{l}\text { Flexibility and efficiency: Users always learn, and users are always different. Give } \\
\text { users the flexibility of creating customizations and shortcuts to accelerate their } \\
\text { performance. }\end{array}$ \\
\hline Message & $\begin{array}{l}\text { Good error messages: The messages should be informative enough such that users } \\
\text { can understand the nature of the errors, learn from the errors, and recover from any } \\
\text { errors. }\end{array}$ \\
\hline Error & $\begin{array}{l}\text { Prevent errors: It is always better to design interfaces that prevent errors from } \\
\text { happening in the first place. }\end{array}$ \\
\hline Closure & $\begin{array}{l}\text { Clear closure: Every task has a beginning and an end. Users should be clearly notified } \\
\text { about the completion of a task. }\end{array}$ \\
\hline Undo & $\begin{array}{l}\text { Reversible actions: Users should be allowed to recover from errors. Reversible actions } \\
\text { also encourage exploratory learning. }\end{array}$ \\
\hline Language & $\begin{array}{l}\text { Use the users' language: The language should be always presented in a form that is } \\
\text { understandable by the intended users. }\end{array}$ \\
\hline Control & $\begin{array}{l}\text { Users in control: Do not give users that impression that they are controlled by the } \\
\text { systems. }\end{array}$ \\
\hline Docur & $\begin{array}{l}\text { Help and documentation: Always provide help when needed, ideally context-sensitive } \\
\text { help. }\end{array}$ \\
\hline
\end{tabular}

The authors received ethical approval from the Ministry of Health in Saudi Arabia and satisfied the requirements of dealing with a human as an object of research.

\subsection{Participants}

Even though radiology technicians are able to operate many radiology machines interchangeably, such as CT scans or MRIs, the study only focused on technicians who were using the CT scan on a daily basis at the time of the study. The total number of participants was $44 \mathrm{CT}$ scan technicians (Table 2 shows demographic characteristics). The technicians were geographically from hospitals in all 13 Saudi regions.

\section{Results}

Cronbach's alpha was conducted to measure the reliability of the questionnaire 
(Table 3). Generally, Cronbach's alpha is acceptable when the value is above 0.80 [13]. All attribute scores were above the acceptable level of 0.80 . In terms of usability catastrophe, all attributes have a usability catastrophe percentage. However, seven usability attributes exceeded the $20 \%$ range:

Table 2. Demographic characteristics.

\begin{tabular}{cccc}
\hline Variables & Column1 & Frequency & $\%$ \\
\hline Gender & Male & 26 & $59.1 \%$ \\
Female & $20-29$ & 18 & $40.9 \%$ \\
& $30-39$ & 14 & $31.8 \%$ \\
Level of Education & $40-49$ & 23 & $52.3 \%$ \\
& Diploma & 7 & $15.9 \%$ \\
& Bachelor & 11 & $25.0 \%$ \\
& Master & 25 & $56.8 \%$ \\
& $0-3$ years & 8 & $18.2 \%$ \\
& $4-7$ years & 16 & $36.4 \%$ \\
& $8-11$ & 9 & $25.0 \%$
\end{tabular}

Table 3. Cronbach's alpha.

\begin{tabular}{ccc}
\hline Usability attribute & No. of items & Cronbach's Alpha \\
\hline Consistency & 6 & 0.947 \\
Visibility & 4 & 0.903 \\
Match & 3 & 0.901 \\
Minimalist & 4 & 0.919 \\
Memory & 5 & 0.934 \\
Feedback & 4 & 0.907 \\
Flexibility & 3 & 0.877 \\
Message & 4 & 0.909 \\
Error & 5 & 0.902 \\
Closure & 3 & 0.913 \\
Undo & 4 & 0.864 \\
Language & 4 & 0.84 \\
Control & 2 & 0.843 \\
Document & 2 & 0.869 \\
\hline
\end{tabular}


- layout and position,

- terminology,

- current state of the system,

- what can be done at the current state,

- progressive levels of detail at $20 \%$,

- concrete examples at $20 \%$, and

- shortcuts for frequently used operations at $27.3 \%$.

These attributes belong to consistency (two attributes), visibility (two attributes), minimalism (one attribute), memory (one attribute), and flexibility (one attribute). Table 4 illustrates the descriptive statistics for all usability attributes. Evidently, the maximum statistic registers as 4, which is a catastrophe for every attribute. This indication shows that users have varied abilities in handling the CT scan. These variations are in accordance with social demographic characteristics. The statistic means were examined, where the uppermost is 2.34, and the lowermost is 1.55 . Figure 2 presents the overall usability score based on the 14 usability attributes. A higher number indicates more usability issues faced by the technicians. As a group, most of the issues were concentrated within the categories of document (56.5\%), flexibility (56\%), and visibility (55.5\%).

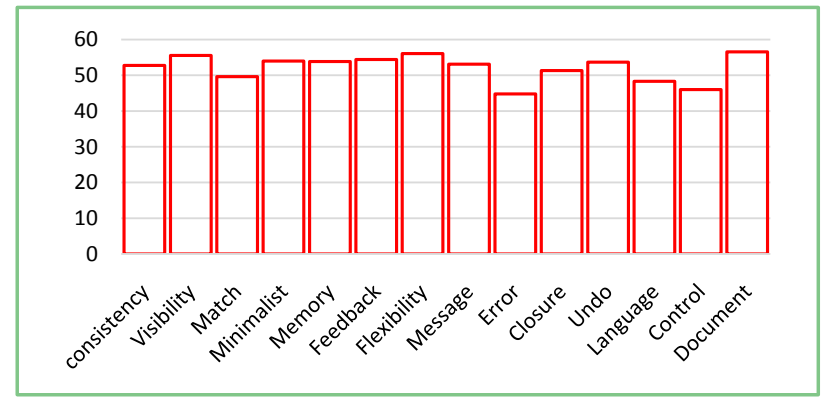

Figure 2. Overall usability percentage encountered by technicians.

Table 4. Descriptive statistics.

\begin{tabular}{lllllll}
\hline & Minimum & Maximum & Mean & & \multicolumn{2}{c}{ Std. Deviation Variance } \\
\cline { 2 - 7 } & Statistic & Statistic & Statistic & Std. Error & Statistic & Statistic \\
\hline Sequences of actions (Consistency) & 0 & 4 & 2.11 & 0.173 & 1.146 & 1.312 \\
Color (categorization) (Consistency) & 0 & 4 & 2.14 & 0.188 & 1.250 & 1.562 \\
Layout and position (Consistency) & 0 & 4 & 2.05 & 0.213 & 1.413 & 1.998 \\
Font, capitalization (Consistency) & 0 & 4 & 2.11 & 0.206 & 1.368 & 1.871 \\
Terminology (Consistency) & 0 & 4 & 2.05 & 0.227 & 1.509 & 2.277 \\
Standards (Consistency) & 0 & 4 & 2.20 & 0.202 & 1.340 & 1.794 \\
the current state of the system (Visibility) & 0 & 4 & 2.23 & 0.210 & 1.395 & 1.947 \\
does the display show where you can go (Visibility) & 0 & 4 & 2.34 & 0.213 & 1.413 & 1.997 \\
Where can users go (Visibility) & 0 & 4 & 2.20 & 0.197 & 1.304 & 1.701 \\
\hline
\end{tabular}




\section{Continued}

\begin{tabular}{|c|c|c|c|c|c|c|}
\hline made change after an action (Visibility) & 0 & 4 & 2.11 & 0.163 & 1.083 & 1.173 \\
\hline User model matches system image (Match) & 0 & 4 & 1.91 & 0.186 & 1.235 & 1.526 \\
\hline $\begin{array}{l}\text { Actions provided by the system match actions } \\
\text { performed by users (Match) }\end{array}$ & 0 & 4 & 1.93 & 0.164 & 1.087 & 1.181 \\
\hline $\begin{array}{l}\text { Objects on the system match objects of the task } \\
\text { (Match) }\end{array}$ & 0 & 4 & 2.11 & 0.204 & 1.351 & 1.824 \\
\hline Less is more (Minimalist) & 0 & 4 & 2.14 & 0.164 & 1.091 & 1.190 \\
\hline Simple is not equivalent to abstract (Minimalist) & 0 & 4 & 2.11 & 0.176 & 1.166 & 1.359 \\
\hline Simple is efficient (Minimalist) & 0 & 4 & 2.14 & 0.171 & 1.133 & 1.283 \\
\hline Progressive levels of detail (Minimalist) & 0 & 4 & 2.25 & 0.203 & 1.349 & 1.820 \\
\hline Perceptual procedures (Memory) & 0 & 4 & 2.20 & 0.194 & 1.286 & 1.655 \\
\hline Hierarchical structure (Memory) & 0 & 4 & 2.30 & 0.183 & 1.212 & 1.469 \\
\hline Default values (Memory) & 0 & 4 & 2.18 & 0.201 & 1.334 & 1.780 \\
\hline Concrete examples (Memory) & 0 & 4 & 1.98 & 0.231 & 1.532 & 2.348 \\
\hline Generic rules and actions (Memory) & 0 & 4 & 2.11 & 0.182 & 1.205 & 1.452 \\
\hline $\begin{array}{l}\text { Information directly perceived, interpreted, and } \\
\text { evaluated (Feedback) }\end{array}$ & 0 & 4 & 2.14 & 0.183 & 1.212 & 1.469 \\
\hline Levels of feedback (Feedback) & 0 & 4 & 2.32 & 0.168 & 1.116 & 1.245 \\
\hline Concrete and specific (Feedback) & 0 & 4 & 2.02 & 0.144 & 0.952 & 0.906 \\
\hline Appropriate Response Time (Feedback) & 0 & 4 & 2.23 & 0.152 & 1.008 & 1.017 \\
\hline Shortcuts for experienced users (Flexibility) & 0 & 4 & 2.32 & 0.189 & 1.253 & 1.571 \\
\hline Shortcuts for frequently used operations. (Flexibility) & 0 & 4 & 2.39 & 0.196 & 1.298 & 1.684 \\
\hline Skill acquisition through chunking (Flexibility) & 0 & 4 & 2.02 & 0.191 & 1.267 & 1.604 \\
\hline Phrased in clear language (Message) & 0 & 4 & 2.14 & 0.199 & 1.322 & 1.748 \\
\hline Precise, not vague or general (Message) & 0 & 4 & 2.34 & 0.189 & 1.256 & 1.579 \\
\hline Constructive (Message) & 0 & 4 & 2.02 & 0.167 & 1.110 & 1.232 \\
\hline Polite (Message) & 0 & 4 & 2.00 & 0.166 & 1.100 & 1.209 \\
\hline Interfaces that make errors impossible (Error) & 0 & 4 & 1.75 & 0.181 & 1.203 & 1.448 \\
\hline Avoid modes (Error) & 0 & 4 & 1.57 & 0.193 & 1.283 & 1.646 \\
\hline Sound Experience (Error) & 0 & 4 & 1.98 & 0.177 & 1.171 & 1.372 \\
\hline Execution error vs. evaluation error (Error) & 0 & 4 & 1.86 & 0.180 & 1.193 & 1.423 \\
\hline Various types of slips and mistakes (Error) & 0 & 4 & 1.80 & 0.183 & 1.212 & 1.469 \\
\hline Clear beginning, middle, and end (Closure) & 0 & 4 & 2.05 & 0.184 & 1.219 & 1.486 \\
\hline Complete 7-stages of actions (Closure) & 0 & 4 & 2.16 & 0.159 & 1.055 & 1.114 \\
\hline $\begin{array}{l}\text { Clear feedback to indicate goals are achieved } \\
\text { (Closure) }\end{array}$ & 0 & 4 & 1.95 & 0.187 & 1.238 & 1.533 \\
\hline $\begin{array}{l}\text { At different levels: a single action, a subtask, or a } \\
\text { complete task. (Undo) }\end{array}$ & 0 & 4 & 1.98 & 0.158 & 1.045 & 1.092 \\
\hline Multiple steps (Undo) & 0 & 4 & 2.09 & 0.165 & 1.096 & 1.201 \\
\hline
\end{tabular}




\begin{tabular}{|c|c|c|c|c|c|c|}
\hline Continued & & & & & & \\
\hline Encourage exploratory learning (Undo) & 0 & 4 & 2.23 & 0.178 & 1.179 & 1.389 \\
\hline Prevent serious errors. (Undo) & 0 & 4 & 2.30 & 0.154 & 1.025 & 1.050 \\
\hline Use standard meanings of words (Language) & 0 & 4 & 1.82 & 0.179 & 1.187 & 1.408 \\
\hline $\begin{array}{l}\text { Specialized language for specialized group } \\
\text { (Language) }\end{array}$ & 0 & 4 & 2.14 & 0.171 & 1.133 & 1.283 \\
\hline User defined aliases (Language) & 0 & 4 & 2.23 & 0.178 & 1.179 & 1.389 \\
\hline Users' perspective (Language) & 0 & 4 & 1.55 & 0.157 & 1.044 & 1.091 \\
\hline Users are initiators of actors (Control) & 0 & 4 & 1.77 & 0.159 & 1.054 & 1.110 \\
\hline Avoid surprising actions (Control) & 0 & 4 & 1.91 & 0.141 & 0.936 & 0.875 \\
\hline Context-sensitive help (Documentation) & 0 & 4 & 2.23 & 0.175 & 1.159 & 1.342 \\
\hline Help embedded in contents & 0 & 4 & 2.30 & 0.161 & 1.069 & 1.143 \\
\hline
\end{tabular}

\section{Conclusion and Discussion}

Despite the heavily regulated practices in radiology, CT scan technicians are overwhelmingly concentrated on delivering images that can be read easily by doctors and interpreters. Undeniably, usability has a profound effect on both technicians and patients. It empowers the technician's ability to execute more tasks within a defined time and reflects on the patient's overall safety. With pressure for resources, technicians tend to maneuver physical exertion by minimizing movement after a certain time. A technician was observed after 4 hours of CT scan operation trying to divert physical movement (going to the exam room to center the patient) by telling the patient to lay down on the table. Then, the technician examined the patient using the repeat series feature without the necessity to go physically into the room to center the patient on the CT scan table. This attitude agrees with the study finding that $27 \%$ of technicians rated CT scans as catastrophic in shortcuts for frequently used operations. Considering that going to the exam room to center the patients is the most frequently used operation while operating a CT scan, one important principle of this study is that CT scan designers should consider enforcing more flexibility in the machine, especially enabling users to easily conduct an exam from the control room without the necessity to summon the technician into the exam room to center and re-center patients. Executing tasks with efficiency might be enough in a particular device, but in a CT scan, it must also come with minimizing physical and mental exertion. Future work will examine the usability for system engineering. A system engineering model will be introduced to handle business intelligence reporting with an emphasis on practical usability principles.

\section{Conflicts of Interest}

The authors declare no conflicts of interest regarding the publication of this paper. 


\section{References}

[1] Aldoihi, S. and Hammami, O. (2018) Evaluation of CT Scan Usability for Saudi Arabian Users. 2018 International Conference on Computer, Information and Telecommunication Systems (CITS), Colmar, 11-13 July 2018. https://doi.org/10.1109/CITS.2018.8440165

[2] Samaras, E.A. and Samaras, G.M. (2016) Confronting Systemic Challenges in Interoperable Medical Device Safety, Security \& Usability. Journal of Biomedical Informatics, 63, 226-234. https://doi.org/10.1016/j.jbi.2016.08.024

[3] Parlangeli, O., Giani, A., Bracci, M., Bonanno, I., Conte, A., Del Priore, V., et al. (2018) User Interface and Operators: Evolution in the Perception of Computed Tomography (CT). In Congress of the International Ergonomics Association (pp. 584-594). Springer, Cham. https://doi.org/10.1007/978-3-319-96077-7_63

[4] Zhang, J., et al. (2003) Using Usability Heuristics to Evaluate Patient Safety of Medical Devices. Journal of Biomedical Informatics, 36, 23-30. https://doi.org/10.1016/S1532-0464(03)00060-1

[5] Côrtes, P.L. and Côrtes, E.G.d.P. (2011) Hospital Information Systems: A Study of Electronic Patient Records. Journal of Information Systems and Technology Management, 8, 131-154. https://doi.org/10.4301/S1807-17752011000100007

[6] Tullis, T. and Albert, B. (2013) Measuring the User Experience. Elsevier, Amsterdam.

[7] Miller, C.A. (2013) Lessons from Another Industry: Aviation, Usability, and Medical Device Design. Biomedical Instrumentation \& Technology, 47, 40-44. https://doi.org/10.2345/0899-8205-47.s2.40

[8] Hegde, V. (2013) Role of Human Factors/Usability Engineering in Medical Device Design. Proceedings Annual Reliability and Maintainability Symposium (RAMS), Orlando, FL, 28-31 January 2013, 1-5. https://doi.org/10.1109/RAMS.2013.6517650

[9] Lang, A.R., Martin, J.L., Sharples, S. and Crowe, J.A. (2013) The Effect of Design on the Usability and Real World Effectiveness of Medical Devices: A Case Study with Adolescent Users. Applied Ergonomics, 44, 799-810. https://doi.org/10.1016/j.apergo.2013.02.001

[10] Vincent, C.J., Li, Y. and Blandford, A. (2014) Integration of Human Factors and Ergonomics during Medical Device Design and Development: It's All about Communication. Applied Ergonomics, 45, 413-419. https://doi.org/10.1016/j.apergo.2013.05.009

[11] Aldoihi, S. and Hammami, O. (2019) Evaluation of Invisible Physical and Mental Exertion from CT Scan Operation in Saudi Arabian Hospitals. 2019 6th International Conference on Control, Decision and Information Technologies (CoDIT) Paris, 23-26 April 2019, 761-766. https://doi.org/10.1109/CoDIT.2019.8820705

[12] Aldoihi, S. and Hammami, O. (2019) Effect of Invisible Exertions on Computed Tomography Radiologists in Saudi Hospitals. 2019 IEEE/ACS 16 th International Conference on Computer Systems and Applications (AICCSA), Abu Dhabi, November 2019.

[13] Field, A. (2018) Discovering Statistics Using IBM SPSS Statistics. 5th Edition, SAGE Publications Ltd., London. 